\title{
PSICOLOGÍA POSITIVA Y EDUCACIÓN FAMILIAR: UNA PROPUESTA DE COMPLEMENTARIEDAD
}

Gabriela Esponda Jones

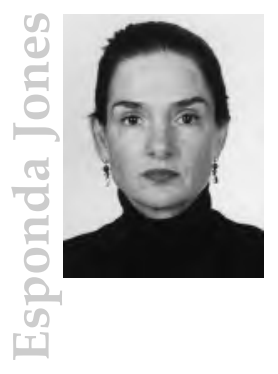

Maestría en Psicología Clínica, Newport University. Licenciatura en Psicología, Universidad Intercontinental. Actualmente proporciona consulta psicoterapéutica para adultos, pareja y familia, e impartición de Talleres para Padres en el ÍTEMS.

Correo electrónico:

[gabrielaesponda@gmail.com].

\section{RESUMEN}

La psicología positiva es una nueva y pujante rama de la psicología tradicional que estudia los estados emocionales positivos de la conducta humana con la finalidad de llevar a cabo una labor preventiva de los padecimientos de orden mental.

Este escrito pretende acercar esta rama de las ciencias de la conducta a la pedagogía - a través de la educación familiar-, mediante la presentación de dos de sus importantes áreas de estudio: el optimismo y la sabiduría. También intenta generar estrategias educativas que faciliten su implementación en la vida familiar. Estos dos aspectos, como todos los que estudia la psicología positiva, son educables. Los elementos que construyen estas actitudes positivas son el material básico para el aprendizaje de razonamientos y hábitos saludables que se traduzcan en una mejor calidad de vida y en la disminución de los índices de disfuncionalidad mental. 
Palabras clave: psicología positiva; educación familiar; prevención; estados emocionales positivos; optimismo; sabiduría; recursos.

\section{ABSTRACT}

This article aims at bringing positive psychology and family education to work together. The purpose of this engagement is to make a joint effort in the prevention of mental disorders.

This article examines only optimism and wisdom for reasons of practicity and space. The analysis offered to the reader contains the elements that constitute these attitudes with the sole purpose of inviting family education to bring forward educational options so as to bring psychological theory to life.

Keys words: positive psychology; family education; prevention; educational options; optimism; wisdom.

\section{INTRODUCCIÓN}

La pedagogía posee una orientación preventiva y, de manera más específica, la educación familiar busca educar para que no haya qué remediar.

Tradicionalmente, la psicología se ha ocupado de remediar y subsanar los padecimientos mentales en la vida del ser humano. Sin embargo, y de manera reciente, ha volcado su interés hacia aquellos estados que lo reconstituyen como persona, aumentando su calidad de vida. Durante el siglo XX, esta disciplina se ocupó de lo disfuncional. Ha llegado el momento de mirar hacia los estados óptimos que promueven su excelencia vital.

La información resultante de las investigaciones de la psicología positiva puede emplearse como información preventiva. La educación familiar puede hacer uso de este cuerpo de conocimientos con la finalidad de inculcar oportunamente en las personas —quizá, más específicamente, en 
los padres de familia-, las cualidades que previenen el deterioro de la salud mental y, por ende, el desarrollo personal pleno.

Este trabajo pretende difundir algunos conceptos de la psicología positiva con la idea de aportar conceptos que puedan incorporarse al acervo de conocimientos y tareas de la educación familiar.

\section{ANTECEDENTES}

El objetivo tradicional de la psicología —en su modalidad terapéutica- ha consistido en comprender los mecanismos de la conducta humana con la finalidad de evaluar, modificar y erradicar el sufrimiento de las personas.

Este interés de la psicología, sesgado hacia los aspectos negativos de la experiencia humana, tiene su razón de ser. Las emociones negativas surgen como un mecanismo de alarma ante situaciones que representan una amenaza para la integridad física o psicológica de quien las vive. Su atención siempre posee carácter de urgente.

Es importante mencionar que este sesgo hacia lo negativo, ha traído consigo grandes y muy útiles aportaciones. A lo largo de las últimas cinco décadas, se han realizado una gran cantidad de investigaciones para comprender los mecanismos que subyacen a factores complejos que abarcan desde los elementos de toxicidad en la familia, hasta el huidizo y difícil problema de abordar la esquizofrenia, entre otros. Y no sólo eso: la psiquiatría ha desarrollado una amplia cantidad de tratamientos farmacológicos que aminoran y corrigen gran parte del sufrimiento emocional de hombres y mujeres.

Las experiencias que traen consigo bienestar, suelen pasar desapercibidas. Es por ello que resulta comprensible y lógico que la psicología no las haya estudiado y sí se haya ocupado de analizar los estados negativos de la psique humana: muchos de ellos representan una llamada a la acción que puede resultar básica para la sobrevivencia física o emocional. 
Por ello, la psicología ha enfatizado los efectos negativos de muchas situaciones tales como la frustración, el enojo, la enfermedad física y sus efectos en la conducta, la disfuncionalidad familiar, las causas de la violencia física, el desvanecimiento del matrimonio, las diferencias de género y sus consecuencias, la homosexualidad, los desórdenes de la personalidad y sus causas, entre otros.

La labor de investigación realizada en las últimas cinco décadas con respecto a los resultados de la psicoterapia, evidencia una realidad contundente: el trabajo psicoterapéutico no ha traído consigo información pertinente a la prevención de los problemas emocionales.

Se ha llegado entonces al momento, como ciencia y como sociedad, de comprender que los estados positivos de la psique humana también poseen un valor fundamental en términos de sobrevivencia y calidad de vida.

\section{PSICOLOGÍA POSITIVA Y EDUCACIÓN FAMILIAR}

La psicología positiva es la parte de la psicología que estudia los factores y mecanismos que acrecientan el bienestar psíquico.

La psicología ha comprendido que la misión no sólo consiste en estudiar la enfermedad y la salud mental; su objetivo también debe centrarse en el proceso de crecimiento del ser humano: se ha dejado atrás la noción de que la persona es un receptor pasivo de sus circunstancias vitales.

La psicología y la educación familiar pueden colaborar para que las personas sean capaces de volverse agentes de su propia vida, y prevenir problemas a través del conocimiento y el ejercicio de sus recursos.

Con este propósito, la psicología se ha avocado recientemente al estudio científico y sistemático de fenómenos tales como la creatividad, el optimismo, la sabiduría, la autenticidad, la capacidad de perdonar, la manera en la que adquirimos el sentido de la moral y el sentido de vida, entre otros asuntos. Se parte de la premisa de que estas conductas 
y actividades actúan como amortiguadores para aminorar y, en ocasiones, erradicar, las enfermedades mentales.

La tarea de utilizar esta información y de concretarla en la vida social, particularmente de niños y jóvenes, ha de recaer en las manos de los educadores.

El trabajo deberá orientarse a hacer del conocimiento general las características humanas positivas antes mencionadas, así como identificar y acrecentar los recursos que las personas ya poseen.

\section{ALGUNOS TEMAS QUE ESTUDIA LA PSICOLOGÍA POSITIVA}

Para los fines de este artículo y por razones de espacio, únicamente se analizarán dos elementos que considero fundamentales: el optimismo y la sabiduría.

\section{Optimismo}

El estudio del optimismo como factor de salud emocional, ha sido investigado por Charles Carver y Michael Scheier (2005). Estos autores, además de realizar investigaciones teóricas, crearon un test que mide el optimismo. Esta prueba recibe el nombre de Life Orientation Test-Revised (LOT-R). Con base en sus investigaciones y trabajo de campo, los autores obtuvieron, entre algunas, importantes conclusiones:

Las personas experimentan una gran variedad de emociones ante las dificultades: miedo, ansiedad, motivación, excitación y depresión, entre otras. El equilibrio y el buen juicio de la realidad con que se vivan las emociones negativas, están relacionados con las actitudes que conocemos con los nombres de optimismo o pesimismo.

El optimismo es una característica de quienes esperan, en términos generales, que les sucedan cosas buenas. Lo contrario aplica para los pesimistas. Estas características entran en acción en el momento en el que se 
nos presenta una dificultad — que suele ser traducida como meta-, para ser abordada con acciones.

Las metas u objetivos son situaciones que se evalúan en términos de «deseables» o «indeseables». Cuando las personas se proponen metas, ajustan sus acciones para alcanzarlas. Pero esto dependerá, en gran medida, de sus expectativas acerca de los resultados.

Las expectativas que poseemos acerca de cualquier situación, inciden fuertemente en el resultado de la misma: inducen en la manera en que la persona abordará dicha circunstancia. En la persona optimista, las expectativas están frecuentemente cargadas de confianza en que el objetivo deseado puede alcanzarse. Por el contrario, el pesimista estará lleno de dudas y titubeos.

Carver y Scheier (2005) citan un vasto número de estudios realizados con enfermos de cáncer, VIH y enfermedades cardíacas entre otras, cuyo objetivo fue determinar las estrategias emocionales que utilizaban estos pacientes. Los optimistas no fijaban tanto su atención en los aspectos negativos de la experiencia; más bien se centraban en planear su recuperación. Algunos más esperaban también lograr una ganancia de tipo personal-espiritual al finalizar este delicado período. Por su parte, los pesimistas se ciclaban más en el dolor y evadían la búsqueda de soluciones a su futuro. Esto generalmente se hacía a través de «cerrar las puertas» a las opciones propuestas por otros. En otras palabras, los optimistas generaban soluciones y los pesimistas se cerraban a nuevas posibilidades.

De estos hechos se deriva que optimistas y pesimistas lo son porque difieren en su estilo de respuesta ante las metas y dificultades. Unos las enfrentan a través de la generación de recursos y posibilidades, y los otros no las enfrentan, más bien las evaden, a través de no generar alternativas o proyectos y de descalificar las posibilidades que se les proponen.

¿Es educable el optimismo? La respuesta es afirmativa. Se puede educar para el optimismo cuando: 
- El objetivo es que las personas aprendan a aceptar que tienen un problema, abordarlo y no evitarlo mediante la reclusión o descalificación de las alternativas.

- Se enseñe a generar alternativas y evaluarlas objetivamente.

- Se inculque la persistencia.

- Se maneje un cambio en las cogniciones negativas de tal manera que se sustituyan por objetividad. La tarea principal será entonces concienciar a la persona de que existen pensamientos negativos automáticos que deben revisarse.

La adquisición de estas habilidades será más viable en la medida en la que la persona sea joven.

\section{Sabiduría}

La sabiduría es un término amplio y elusivo, difícil de definir. Popularmente es entendida como un conocimiento especial, reservado sólo para aquellas personas, generalmente mayores, que han profundizado y optimizado sus conocimientos y experiencias de vida descubriendo así ciertos «secretos» que conducen al equilibrio emocional y a la serenidad concomitantes a ella. Según la creencia común, esta riqueza no es comprendida por cualquiera. Es propia de unos cuantos. Se espera del sabio que beneficie generosamente a los demás a través de sus consejos.

La psicología positiva no pretende ni puede estudiar la sabiduría en su sentido más amplio. La sabiduría posee aspectos espirituales que la ciencia jamás podrá medir. A lo que sí puede aspirar es a comprender y tipificar las conductas y cogniciones asociadas con la sabiduría.

La psicología positiva define a la sabiduría como una cualidad altamente adaptativa. Baltes y Glück (2005) afirman que su aspecto medular es la claridad con respecto a la comprensión de los sistemas subyacentes a las relaciones humanas, pero no sólo a nivel conductual, sino también a nivel afectivo. Esta capacidad trae consigo la posibilidad de planear y mantener una buena vida, así como la de propiciar el bienestar de los demás. 
Baltes y Glück (2005) también señalan que la sabiduría se compone por elementos tales como la competencia socio-emocional y la creatividad en la solución eficiente de problemas para adaptarse a las nuevas demandas y cambios del entorno. Estas competencias traerán consigo un mejor manejo de la incertidumbre y de los desafíos que implica el devenir de la vida.

A continuación se presenta un breve análisis de dichos elementos:

\section{Competencia socio-emocional:}

Como es evidente, este componente de la sabiduría se adquiere a través del intercambio y las relaciones con los demás. Implica la habilidad para descifrar las emociones del otro y las propias. Según Reuben Bar-On (2007), las personas con una adecuada inteligencia emocional son capaces de:

1) Entenderse a sí mismas y expresarse en concordancia.

2) Entender a los demás y relacionarse adecuadamente con ellos.

3) Resolver exitosamente las exigencias de la vida cotidiana.

Por su parte, Daniel Goleman (2007) afirma que la inteligencia social abarca dos grandes campos. Uno de ellos es la conciencia social (esto es, la comprensión del estado interno del otro), y el segundo es la habilidad para lo social (esto es, la capacidad para que las interacciones entre las personas sean efectivas o fluidas).

La conciencia social abarca cuatro aspectos fundamentales:

- Empatía primaria: sentir con el otro.

- Sintonización: escuchar con genuina receptividad.

- Precisión empática: comprender los pensamientos, las emociones y las intenciones del otro.

- Cognición social: conocimiento acerca de las normas que hacen funcionar a la sociedad en la que se vive.

La habilidad para lo social comprende, también, cuatro elementos principales:

- Sincronización con el pensamiento y emoción del otro.

- Auto presentación adecuada. 
- Capacidad para influenciar el resultado deseado de las interacciones sociales.

- Consideración a las necesidades ajenas y respuesta congruente con ellas.

\section{Creatividad en la solución de problemas:}

Según Heather Cattell (1993), la creatividad es la capacidad de generar soluciones a los problemas para los cuales el ambiente no ofrece medios adecuados, eficaces o automáticos de solución.

En su libro sobre creatividad, Keith Sawyer (2006) menciona ciertos elementos que, combinados, conducen a la solución creativa de los problemas.

Uno de ellos es la evaluación adecuada del problema. Este paso se concreta en la medida en que se encuadran los problemas, se examina cuidadosamente la información y se construyen oportunidades.

Otro elemento que conduce a la creatividad es la generación de ideas para contar con un repertorio rico de posibilidades de dónde elegir. Resulta importante diferir los juicios y buscar el común denominador de todas las ideas generadas.

Finalmente, esta propuesta sugiere crear soluciones considerando los elementos anteriores pero, además, llevar a cabo un ejercicio de juicio adecuado para discernir las posibilidades realistas de las que no lo son.

¿Es educable la sabiduría? Lo es, en la medida en la que pueda enseñarse a las personas a razonar sobre sus emociones y a adquirir las habilidades necesarias para modularlas y precisarlas. La educación de la sabiduría también requiere que las personas aprendan a acceder a sus propias emociones para conectarse empáticamente con los otros, así como adquirir el vocabulario necesario para expresar todo esto con precisión.

Cattell (1993) también nos proporciona pautas educativas. Ella afirma que la resolución adecuada de problemas requiere de anticipación, juicio, 
planificación, examen de la realidad, memoria y autorregulación. Todas estas actitudes pueden ser aprendidas.

La creatividad en la solución de problemas también abre un vasto campo de acción para la educación familiar. Un aspecto educable que considero sobresaliente es la capacidad de generar un repertorio amplio de posibilidades. Las personas tendemos a quedarnos con dos: sí o no. De la misma forma, parece fundamental el ejercicio y la práctica de un juicio objetivo sobre la realidad.

\section{CONCLUSIONES}

La psicología positiva, rama de la psicología tradicional, está en sus albores. La justificación de su existencia, como parte importante de la psicología, radica en que los conocimientos que aporte resulten útiles en la vida diaria de hombres y mujeres. Creo que la educación familiar es la mancuerna indispensable para que esto se implemente. Podemos afirmar que la psicología aporta el «qué» y la educación familiar aporta el «cómo».

Muchas de las contribuciones prácticas mencionadas en este trabajo no son del todo novedosas. Sin embargo, su aportación radica en que la práctica de estas tareas conlleva la prevención de desórdenes de la personalidad, así como de otros padecimientos mentales.

Hoy, más que nunca, la familia necesita orientación. Estamos inmersos en un mundo lleno de incertidumbres que requieren suplantarse por certidumbres. La educación familiar es uno de los caminos más viables para lograrlo. 


\section{BIBLIOGRAFÍA}

BALTES, P. \& GLÜCK, J., «Wisdom: It's Structure and Function in Regulating Successful Life Span», in SNYDER, C.R., LÓPEZ, S. (comp.), Handbook of Positive Psychology, Oxford University Press, USA, 2005, $327 \mathrm{p}$.

BAR-ON, R. \& ELIAS, M.J., Educating People to be Emotionally Intelligent, Praeger, USA, 2007, 344 p.

CARVER, C. \& SCHEIER, M., «Optimism», in SNYDER, C.R. \& LÓPEZ, S. (comp.), Handbook of Positive Psychology, Oxford University Press, USA, 2005, 244 p.

CATTELL, H., Lo profundo de la personalidad, Ed. Manual Moderno, México, 1993, 38 p.

GOLEMAN, D., Emotional Intelligence, Bantam, USA, 1997, 42 p.

GOLEMAN, D., Social Intelligence, Bantam, USA, 2007, 84 p.

SAWYER, K., Explaining Creativity, Oxford University Press, USA, 2006, 299 p. 